
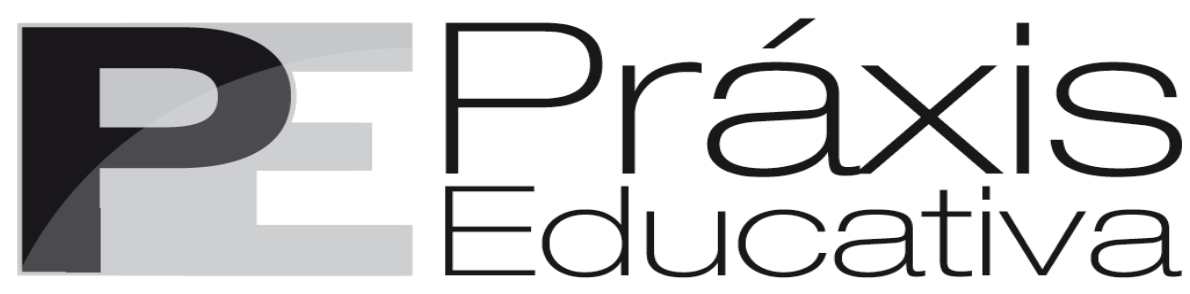

ISSN 1809-4031

eISSN 1809-4309

https://doi.org/10.5212/PraxEduc.v.16.16556.052

\title{
O diálogo como experiência constituinte na formação inicial do professor de Matemática
}

\section{Dialogue as a constituent experience in the initial training of the Mathematics teacher}

\section{E1 diálogo como experiencia constituyente en la formación inicial del profesor de Matemáticas}

Francisco Jeovane do Nascimento* D https://orcid.org/0000-0001-9753-724X

Eliziane Rocha Castro ${ }^{* *}$

(D) https: / / orcid.org/0000-0002-4870-6905

Luciana Rodrigues Leite ${ }^{* * *}$

(iD) https://orcid.org/0000-0003-1915-6462

Maria Socorro Lucena Lima ${ }^{* * *}$

(iD) https:// orcid.org/0000-0001-6600-1194

Resumo: Baseado nas premissas freireanas, este trabalho explicita a relevância dialógica na formação inicial docente, sendo resultante de uma experiência desenvolvida no contexto do Estágio Supervisionado com 14 licenciandos do curso de Matemática da Universidade da Integração Internacional da Lusofonia AfroBrasileira (UNILAB). Nesta investigação, o diálogo assume a condição de categoria teórica, e os pressupostos metodológicos estão fundamentados na abordagem qualitativa. As reflexões oriundas deste momento dialógico evidenciam a importância do contato de professores em formação com profissionais

\footnotetext{
* Doutorando do Programa de Pós-Graduação em Educação da Universidade Estadual do Ceará (PPGE-UECE). Professor da Rede Estadual de Ensino do Ceará (SEDUC/CE) e Bolsista da Fundação Cearense de Apoio à Pesquisa (FUNCAP). E-mail: <jeonasc@hotmail.com>.

** Doutoranda do Programa de Pós-Graduação em Educação da Universidade Estadual do Ceará (PPGE-UECE). Coordenadora do Núcleo de Formação Continuada da Secretaria Municipal de Educação de Raposa, Maranhão. Email: <elizianecastro@hotmail.com>.

*** Doutoranda do Programa de Pós-Graduação em Educação da Universidade Estadual do Ceará (PPGE-UECE). Programa de Pós-Graduação em Educação. Professora na Universidade Estadual Vale do Acaraú (UVA), Ceará. Email: <lurodleite@gmail.com>.

**** Doutora em Educação pela Universidade de São Paulo (USP). Professora do Programa de Pós-Graduação em Educação da Universidade Estadual do Ceará (PPGE-UECE). E-mail: <socorro_lucena@uol.com.br>.
} 
mais experientes e fortalecem o Estágio Supervisionado como oportunidade de contato com práticas e saberes diversificados, além do conhecimento da complexidade que permeia a escola.

Palavras-chave: Diálogo freireano. Estágio Supervisionado. Formação inicial do professor de Matemática.

Abstract: Based on the Freirean premises, this work makes explicit the dialogical relevance in initial teacher training, being the result of an experience developed in the context of the Supervised Internship with 14 undergraduate students of the Mathematics course of the University for International Integration of the Afro-Brazilian Lusophony (UNILAB). In this investigation, the dialogue assumes the condition of theoretical category, and the methodological assumptions are based on the qualitative approach. The reflections coming from this dialogic moment highlight the importance of the contact of teachers in training with more experienced professionals and strengthen the Supervised Internship as an opportunity to contact diverse practices and knowledge, beyond the knowledge of the complexity that permeates the school.

Keywords: Freirean dialog. Supervised Internship. Initial training of the Mathematics teacher.

Resumen: Basado en las premisas freireanas, este trabajo explicita la relevancia dialógica en la formación inicial docente, siendo resultante de una experiencia desarrollada en el contexto de las Prácticas Supervisadas con 14 estudiantes de la carrera de Matemáticas de la Universidad de la Integración Internacional de la Lusofonia Afro-Brasileña (UNILAB). En esta investigación, el diálogo asume la condición de categoría teórica y los presupuestos metodológicos están fundamentados en el enfoque cualitativo. Las reflexiones oriundas de este momento dialógico evidencian la importancia del contacto de profesores en formación con profesionales más experimentados y fortalecen las Prácticas Supervisadas como oportunidad de contacto con prácticas y saberes diversificados, además del conocimiento de la complejidad que impregna la escuela. Palabras clave: Diálogo freireano. Prácticas Supervisadas. Formación inicial del profesor de Matemáticas.

\section{Introdução}

A onda neoconservadora que emerge no contexto social contemporâneo, mediante oposição aos preceitos da Pedagogia Freireana, origina-se pela imposição de um viés ideológico de dominação e de alienação, que, pautado nas necessidades da elite burguesa, se contrapõe à efetivação dialógica no contexto social. Diferentemente, Paulo Freire propõe uma pedagogia crítica que objetiva conhecimento, mobilização e transformação da realidade, com melhorias para todos e não apenas para determinado grupo de pessoas.

Baseado nas premissas freireanas, o presente trabalho explicita a relevância dialógica na formação inicial docente, resultante de uma experiência desenvolvida com licenciandos do curso de Matemática da Universidade da Integração Internacional da Lusofonia Afro-Brasileira (UNILAB). É uma instituição de Ensino Superior pública caracterizada pela iniciativa integrativa entre povos que integram a Comunidade dos Países de Língua Portuguesa (CPLP) - Angola, Brasil, Cabo Verde, Guiné-Bissau, Moçambique, Portugal, São Tomé e Príncipe, Timor Leste - e se propõe a contribuir no conhecimento e na valoração das diferentes culturas que a integram, além de estimular a cooperação internacional em fatores vinculados à educação e ao desenvolvimento científico (BRASIL, 2010).

A experiência dialógica relatada neste escrito foi realizada em março de 2019, por intermédio de atividades planejadas e executadas no contexto do Estágio Supervisionado do referido curso, concentrando-se em um período de três horas, no decurso da aula, realizada no turno vespertino. Participaram dessa experiência formativa licenciandos e um docente da Educação Básica, o qual, com sua bagagem de conhecimentos e experiências, recebeu o convite para um momento formativo, mediado pelo diálogo, com os professores de Matemática em formação.

A experiência formadora foi estabelecida pela troca de conhecimentos dos sujeitos, amparada nas discussões problematizadoras das atividades de regência desenvolvidas pelos futuros

Práxis Educativa, Ponta Grossa, v. 16, e2116556, p. 1-14, 2021

Disponível em: < https://www.revistas2.uepg.br/index.php/praxiseducativa> 
professores no âmbito do Estágio. Essas atividades potencializaram o arcabouço e o delineamento de um repertório próprio de saberes inerentes aos conhecimentos específicos e didáticos/pedagógicos, necessários para a inserção e a continuidade do trabalho em sala de aula.

Como ação inicial, no contexto da aula, o professor convidado discorreu acerca da sua trajetória pessoal, formativa e profissional e, no decorrer da exposição, foi inquirido sobre elementos e fatores que perpassam a formação e o exercício docente, tais como a formação inicial, a iniciação profissional, bem como a prática do professor de Matemática e as suas condições efetivas de trabalho e de formação contínua. Ressalta-se que, em vez de desenvolver uma atividade diretiva, permeada exclusivamente no discurso do professor convidado, trilhou-se o caminho de escuta e de problematização, o que possibilitou que os temas de discussão adviessem dos interesses, dos anseios e dos questionamentos dos licenciandos. Adotou-se essa perspectiva a partir da compreensão de Nery e Barbosa (2021), de que a formação, amparada na teoria freireana, deve ir para além dos discursos, enquanto ação e reflexão.

Nesta investigação científica, o diálogo assumiu, portanto, a condição de categoria teórica, pautada em sua função particularizadora e mediativa entre sujeitos, permeando a escuta reflexiva, em uma análise das potencialidades, limitações, dificuldades e possibilidades de atuação do professor de Matemática em um contexto específico. Importa conhecer o contexto que circunda a instituição escolar, bem como os sujeitos que a compõem, estabelecendo elos e pontos comuns de compreensão da realidade, para nela intervir e transformá-la (FREIRE, 2009).

O diálogo, para Freire (2006), perpassa a exposição crítica de fatores e de elementos que circundam a ação, potencializando sua compreensão, no intuito da tomada de decisões que favoreçam o coletivo e a construção de uma visão emancipatória, de busca por subsídios que beneficiem o grupo, em um viés de superação de pensamentos e de atitudes meramente individualizadoras e ingênuas, que podem contribuir na alienação do indivíduo e na aceitação da realidade, mediante um comodismo conducente à exclusão social.

Nesse contexto, a tessitura deste trabalho foi edificada com a compreensão de que a formação inicial docente pode constituir-se em um momento de estímulo ao trabalho cooperativo, a partir do diálogo coletivo como meio de problematizar situações complexas com as quais os indivíduos se defrontam em seu cotidiano. Busca-se por soluções viáveis para os problemas do contexto em que desenvolvem sua atividade profissional, além da valorização da opinião crítica do grupo de professores, assim como o desenvolvimento de suas capacidades crítico-argumentativas, por intermédio da instauração de contextos escolares colaborativos, pautados no compartilhamento dialogado de conhecimentos, estratégias e objetivos comuns que possam beneficiar o grupo. Requer-se, assim, o engajamento dos profissionais na premência de melhorias coletivas que beneficiem os professores, os alunos, a escola e o contexto que a circunda (PIMENTA; LIMA, 2012).

\section{Dialogando sobre a dialogicidade freireana}

Os professores não ensinam apenas conteúdos. Através de sua prática, também ensinam como pensar criticamente. Se somos progressistas, então ensinar, para nós não é depositar pacotes de conteúdo na consciência vazia dos alunos Paulo Freire (2006, p. 27).

Essa epígrafe reitera o fato de Paulo Freire considerar o diálogo uma necessidade da existência humana. Para ele, o caráter dialógico impõe-se como o caminho pelo qual os homens encontram seu significado enquanto homens. Isso se mostra possível por meio da proposição de ações que visem para além da instrução e estejam empenhadas no papel de educar. Para tanto, o

Práxis Educativa, Ponta Grossa, v. 16, e2116556, p. 1-14, 2021 Disponível em: < https://www.revistas2.uepg.br/index.php/praxiseducativa> 
âmbito educacional precisa ser percebido como espaço de práticas libertadoras e não de dominação, um espaço de vivências e de convivências, tendo o sujeito como produtor de conhecimentos, transformador do mundo e não apenas receptor do outro. Freire (2009) propõe, então, práticas que visem a desocultação das relações de contradição em que a sociedade está inserida, no intuito de contribuir para a construção de uma consciência crítica.

As proposições de Freire opõem-se à neutralidade da educação e envolvem o diálogo como espaço de respeito às opiniões diversas, de envolvimento na escuta, no silêncio e no tratamento de todos como iguais. É com base nesses pressupostos que Paulo Freire aponta a problematização como o caminho para a conscientização crítica dos homens e ressalta que a ausência de diálogo verticaliza a ação, devido à ausência de problematização, pois, conforme ele mesmo afirma, "[...] quem dialoga, dialoga com alguém sobre alguma coisa" (FREIRE, 2013, p. 142).

Nesse sentido, mostra-se perceptível, nas ideias de Freire, a relação dialética da ação humana e uma contraposição à visão tradicional de escola e às teorias sociais e culturais de reprodução humana, mediante a proposição de uma pedagogia crítica, a qual Franco (2017) chama de pedagogia crítico-emancipatória. Esta vem conferir um novo panorama à epistemologia pedagógica, mesclando diversas concepções filosóficas e carregando uma proposta eminentemente política, não conivente com a da ideologia da classe dominante. Segundo o patrono da educação brasileira, a educação tem o papel de conduzir o homem na busca pela constituição de sua autonomia, levando em conta tanto a vocação ontológica do sujeito - vocação de ser - quanto as condições nas quais ele vive - contexto (FREIRE, 2013).

Fundamentado, portanto, em perspectivas emancipatórias, este trabalho ampara-se na compreensão de que: "A educação é comunicação, é diálogo, na medida em que não é a transferência de saber, mas um encontro de sujeitos interlocutores que buscam a significação dos significados" (FREIRE, 2011, p. 60). Por conseguinte, a proposta dialógica, aqui empreendida, busca agregar uma dose de que-fazer problematizador ao cotidiano formativo de futuros docentes, por intermédio dos pressupostos gnosiológicos de uma formação dialógica, que concebe a aula enquanto espaço de encontro entre sujeitos cognoscentes na busca pela construção de conhecimentos (objeto cognoscível), de modo colaborativo, por meio do questionamento a si mesmo e ao outro.

Para Freire (2012, p. 118): “O diálogo tem significação precisamente porque os sujeitos dialógicos não apenas conservam sua identidade, mas a defendem e assim crescem um com o outro. O diálogo, por isso mesmo, não nivela, não reduz um ao outro”. É nessa acepção que este grande pensador da educação defende a necessidade de considerar-se a voz e a visão de mundo do aluno. Perspectiva que, segundo ele, é um dos pilares fundamentais no qual o educador deve apoiar sua prática.

O diálogo na educação freireana possui três dimensões: uma existencial (humanista), outra ético-política e, por fim, metodológica, haja vista que a abordagem dialógica proposta por Paulo Freire viabiliza aos sujeitos a aquisição/construção de conhecimentos (OLIVEIRA, 2017). Nesta última dimensão, podem ser inclusos os círculos de cultura, que, didaticamente, são organizados nos seguintes momentos: a) investigação do universo vocabular, ou levantamento das palavras de uso corrente pelo grupo social; b) extração das palavras geradoras, que orientarão os debates e constituirão o tema gerador geral; c) tematização, no qual os temas e as palavras geradoras são desenvolvidos na busca pela construção do vivido; d) problematização, a partir das situações que emergirem do diálogo entre educador e educandos (FREIRE, 2009). 
Francisco J. do Nascimento, Eliziane Rocha Castro, Luciana R. Leite e Maria Socorro Lucena Lima

\section{Trajeto metodológico}

O estudo está embasado na abordagem qualitativa da pesquisa, em consonância com André (2013), ao afirmar que, nessa perspectiva, o foco remete ao processo e à sua significação, mediada por vivências e experiências dos sujeitos em um determinado contexto, em que importa conhecer e explorar na busca compreensiva e sistematizadora de conhecimentos que alicerçam o campo educacional. $\mathrm{Na}$ perspectiva qualitativa de uma investigação no campo educacional, o rigor científico evidencia-se pela explicitação clara dos passos e das ações delineadas na realização do estudo, requerendo adequação às questões éticas, oportunizando análises e inferências críticas dos leitores e servindo de mote para outros estudos (ANDRÉ, 2013).

A atividade foi desenvolvida no mês de março de 2019, como ação inerente à disciplina de Estágio Supervisionado e oriunda de sugestão exposta pelos próprios licenciandos, que propuseram à professora titular da disciplina a realização do momento. Diante disso, foi feito o convite a um professor da Educação Básica para um momento dialógico com os acadêmicos de Matemática da UNILAB, em que este se dispôs a participar, de forma voluntária, do diálogo formativo.

A experiência dialógica na formação inicial dos professores de Matemática, apresentada e discutida neste trabalho, foi desenvolvida na UNILAB, no campus dos Palmares, situado no município cearense de Acarape, localizado na região intermediária de Fortaleza (região imediata de Redenção-Acarape), que faz parte do Maciço de Baturité, distando $61,8 \mathrm{~km}$ da capital (IBGE, 2020). Nesse campus, funciona um curso de Licenciatura em Matemática da referida Universidade.

No dia da realização da atividade, estavam presentes 14 estudantes da disciplina de Estágio Supervisionado (11 do sexo masculino e três do sexo feminino). Em conformidade com as adequações às normas éticas da pesquisa, os nomes dos licenciandos não serão divulgados neste escrito, uma vez que o foco do estudo remete a fins de cientificidade, sem exposição dos sujeitos a situações que pudessem lhes causar prejuízos e/ou danos materiais, em consonância com as orientações de Severino (2014). Nesses termos, os sujeitos foram cognominados conforme a ordem de participação e exposição de questionamentos, utilizando-se a denominação Estudante 1, por este ter se constituído como o primeiro indivíduo a realizar perguntas e, assim, sucessivamente.

No momento do convite, a professora de Estágio conversou com o professor convidado para repassar-lhe alguns dos questionamentos/anseios recorrentes entre os licenciandos acerca da docência, por ocasião de suas regências. Ela solicitou, também, que o diálogo a ser desenvolvido permeasse a trajetória pessoal, formativa e profissional do professor convidado, com espaço para a discussão/problematização por parte dos acadêmicos, mediante o estabelecimento de uma relação horizontal de reflexão.

Como procedimento metodológico, foi utilizada a observação, e como instrumento de recolha de dados, o diário de campo, que consistiu na anotação das ações desenvolvidas no contexto investigado, bem como do discurso produzido pelos sujeitos. O material de análise para interpretações e inferências deu-se a partir da realização do diálogo entre o professor da Educação Básica (professor convidado) e os futuros professores de Matemática (licenciandos).

Os dados coletados foram analisados por meio da técnica de análise temática de conteúdo. Foi do contexto dialógico que emergiram as categorias, apresentadas e analisadas na seção seguinte, e oriundas dos temas recorrentes e de maior interesse/discussão da referida atividade dialógica, com base nas seguintes etapas: preparação do material, seguida de uma leitura flutuante e identificação dos temas que se repetiam com maior frequência. E, por fim, procedeu-se a uma nova

Práxis Educativa, Ponta Grossa, v. 16, e2116556, p. 1-14, 2021

Disponível em: < https://www.revistas2.uepg.br/index.php/praxiseducativa> 
exploração do material, seguida da categorização final, por intermédio do processo de codificação e de classificação (BARDIN, 2011).

\section{Desenvolvimento das atividades}

Inicialmente, a professora da disciplina de Estágio Supervisionado, responsável pela sua condução e pelo convite do professor da Educação Básica, realizou a apresentação do convidado, expondo, também, a finalidade da experiência formativa, com o objetivo de estabelecer um diálogo efetivo e potencializador de compartilhamento de conhecimentos, aprendizagens e desafios que permeiam a docência em Matemática.

Conforme o relato da professora titular, os licenciandos sugeriram o momento formativo em decorrência das experiências vivenciadas no âmbito das regências inerentes ao Estágio Supervisionado, no qual buscavam analisar os limites e as possibilidades de elementos que são necessários para a atuação do professor de Matemática e que permeiam sua vida e ação profissional. E, assim, o diálogo efetivou-se como possibilidade de fortalecimento da formação inicial dos sujeitos.

Em relação às potencialidades do Estágio, Lima (2012) evidencia que essa etapa formativa se constitui como um momento de aprendizagem da profissão, de modo a interligar conhecimentos específicos e didático-pedagógicos, que atrelados podem fortalecer o repertório docente. Nesse sentido, as vivências podem reverberar em análises sobre a complexidade que perpassa o contexto educacional e vislumbrar a necessidade de constituir-se um eterno aprendiz da profissão, por intermédio das transformações científicas e tecnológicas constantes que se expõem no âmbito social.

Assim, a efetivação desse âmbito formativo (o Estágio) requer o desenvolvimento de ações que contemplem as necessidades dos licenciandos, em busca do estabelecimento dialógico entre formadores/formandos, com o objetivo de reverberar na constituição de um repertório profissional interligado ao que o professor precisa para desenvolver sua atividade em um contexto específico. Pode-se, assim, contribuir em uma transição mais efetiva e propulsora de aprendizagens entre a formação inicial e a inserção no contexto escolar, como professor em uma turma de Educação Básica.

No momento seguinte, o professor de Matemática da Educação Básica evidenciou, de maneira breve e sucinta, seu percurso pessoal, formativo e profissional. Ele afirmou que possuía seis anos de experiência como educador e que atuava em turmas da modalidade do Ensino Fundamental e do Ensino Médio. O docente explicitou sobre seu processo de formação inicial, sua inserção profissional, sobre a prática reflexiva como elemento ressignificador da ação, ancorada pela teoria, sobre as condições de trabalho nos contextos escolares, a importância da formação ao longo da carreira, além de histórias de fracasso e de sucesso que acompanharam o seu percurso de atuação no âmbito da docência.

Nesse aspecto, Nóvoa (2009) afirma a impossibilidade dissociativa entre os aspectos pessoais e profissionais, em que tais vivências estão interligadas e propiciam momentos de aprendizagem que reverberam na vida e no trabalho docente. Para isso, requer-se a reflexão do sujeito, de modo a redirecionar ações e princípios que se fazem presentes em sua prática, em suas atitudes e em seus valores. O objetivo são melhorias da pessoa e do professor, de forma a reverberar em um processo de ensino mais qualificado, que repercuta na aprendizagem dos estudantes e do próprio docente. 
No momento posterior, os licenciandos tiveram a oportunidade de estabelecer um diálogo formativo, com a elaboração de questionamentos sobre elementos e fatores que se fizeram/fazem presentes no percurso de vida, de trabalho e de formação do professor da Educação Básica. Buscou-se, com isso, respostas às suas inquietações individuais e coletivas, a partir do diálogo com os colegas licenciandos e com o professor convidado. Nesse aspecto, os temas foram surgindo de modo espontâneo e são apresentados/discutidos nos tópicos seguintes.

\section{Processo formativo inicial}

A primeira indagação dos licenciandos referiu-se às reverberações do processo formativo inicial na ação docente, em que foi explicitado o seguinte questionamento: "Quais as contribuições e limitações do processo formativo inicial, que o senhor vivenciou, para o trabalho docente?" (Estudante 1). O professor de Matemática da Educação Básica respondeu o seguinte:

A formação inicial representa um momento de preparação formal para o exercício docente, em adequação às questões legislatórias educacionais. Desse modo, para desenvolver esta profissão, é necessário possuir habilitação em nível superior. Como aspecto limitador da formação inicial, enfatizo o privilégio aos conhecimentos específicos, em oposição à equidade com as questões didático-pedagógicas, uma vez que estes são elementos constituintes do repertório de estratégias docentes. Destaco as contribuições do Estágio como campo de conhecimento da complexidade que perpassa à docência, em que as experiências que vivenciei buscaram estabelecer relação dialógica com alunos, professores e gestão, em situações reais de ensino, se constituindo como fator de análise, reflexão e aprendizagem da docência. (Professor de Matemática. Dados da pesquisa).

A fala do professor evidencia a importância do trabalho equitativo entre aspectos teóricopráticos, no processo formativo inicial, e coaduna com o pensamento de Lima (2012), quando esta afirma que a formação inicial deve promover ações que provoquem um diálogo efetivo entre os conteúdos curriculares a serem ensinados com as formas de sua sistematização, de modo a potencializar-se como um momento oportuno de aprendizagem da profissão docente. O professor convidado explicitou, também, a relevância do diálogo no ambiente escolar, de forma que tal fator possibilite a busca pela instauração de um ambiente profícuo aos processos de ensino e de aprendizagem, pautado pelo respeito e pela ajuda mútua, repercutindo em aspectos disciplinares, acolhimento e empatia no contexto escolar e social, conforme expõem Santos e Rodrigues (2013).

O futuro professor deve compreender a importância da análise reflexiva de sua prática e atuação, perceber-se como ser com capacidades e potencialidades que devem ser aprimoradas/aperfeiçoadas e vislumbrar caminhos conducentes a um processo de ensino e de aprendizagem qualificado. Deve, também, remeter-se à busca por subsídios que possam auxiliar em sua ação cotidiana e observar que o conhecimento não é algo estanque, mas que se constrói coletivamente. Nesse sentido, as disciplinas de Estágio Supervisionado e de Prática de Ensino podem contribuir no alcance de tal finalidade. Lopes (2009, p. 44) complementa essa perspectiva ao afirmar que "[...] não existem fórmulas prontas para enfrentar todos os problemas do dia-a-dia da sala de aula, acreditamos que existem modos de aprender a buscar encaminhamentos para a diversidade dos acontecimentos cotidianos".

Como ação limitadora, o professor citou a ênfase em conhecimentos específicos da profissão, que são importantes e essenciais para o trabalho docente, mas que não se esgotam em si mesmos e precisam estar atrelados a maneiras de sistematização que propiciem entendimento e aprendizagem por parte dos estudantes, já que ensinar não é apenas reproduzir, e aprender não é apenas decorar o conteúdo. Nesse aspecto, Nascimento et al. (2018) afirmam que apenas a exposição oral não se constitui como fator indicativo de uma aula que desperte o interesse dos

Práxis Educativa, Ponta Grossa, v. 16, e2116556, p. 1-14, 2021 
estudantes, pois requer o atrelamento de outros mecanismos que agucem a curiosidade dos estudantes, sem perder de vista o rigor científico e a adequação à utilização de conhecimentos didático-pedagógicos que perpassem a ação docente.

Após a resposta do professor convidado, o Estudante 1 expôs o seguinte:

Nas aulas de regência do Estágio, sempre busco estabelecer contato efetivo com os professores que já atuam e dialogar acerca de possibilidades de atuação no âmbito da sala de aula. Procuro envolver os estudantes na construção do seu próprio conhecimento, averiguar os saberes prévios deles, contextualizar o conteúdo e incentivá-los a questionarem, de forma que estes possam vislumbrar a Matemática não como um amontoado de fórmulas e conceitos, mas como instrumento de interpretação e intervenção na e sobre a realidade. (Estudante 1. Dados da pesquisa).

A fala do licenciando revela que as experiências que os futuros professores vivenciam em seu processo formativo inicial devem constituir-se não apenas em momentos de identificação de falhas e deficiências da escola e dos agentes que a compõem, mas de análise, de compreensão e de problematização das múltiplas situações que se expõem no cotidiano escolar. O intuito é que se estabeleçam ambientes coletivos dialógicos de busca por soluções viáveis para tais dilemas, troca mútua de conhecimentos e ações que possam reverberar nos processos de ensino e de aprendizagem discentes, assim como no aperfeiçoamento dos profissionais e da escola, conforme evidenciam Nascimento et al. (2018).

Nessa perspectiva, Lima (2012) afirma que o professor deve vislumbrar-se como um eterno aprendiz da docência, baseado no que vivencia em sua carreira profissional, do contato com alunos e professores com bagagens de conhecimentos e experiências diversificadas, em que o diálogo se evidencie como forma de discussão e de análise dos impactos provenientes do seu trabalho, de forma a repercutir em aspectos pessoais e profissionais.

\section{Iniciação profissional}

O Estudante 2 inquiriu sobre o processo de iniciação profissional. Ele indagou o professor com o seguinte questionamento: "Como foi o acolhimento no contexto de trabalho, quando o senhor foi atuar como professor em uma escola e quais as dificuldades enfrentadas em tal período?”. O docente convidado respondeu:

\footnotetext{
O início da atuação profissional se configura como algo desafiador e complexo, em que se requer auxílio e apoio por parte da gestão escolar e dos pares, no que concerne ao conhecimento das especificidades da instituição escolar e dos alunos, almejando planejar aulas direcionadas às necessidades discentes e em consonância com elementos culturais e sociais do contexto. Fui bem acolhido na escola, quando iniciei. Contudo, tive que enfrentar de forma individualizada as adversidades de início da profissão, visto que, no contexto escolar em que estava inserido, imperava o individualismo e o isolamento docente, em oposição à colaboração, e recebi a incumbência de responsabilidade pelas mesmas ações designadas aos professores mais experientes. (Professor de Matemática. Dados da pesquisa).
}

O relato do professor evidencia que a iniciação profissional se configura como um momento de transição entre a formação inicial e a atuação como professor em uma sala de aula, o qual necessita de diálogo, acolhimento e apoio por parte da gestão e dos colegas mais experientes. Isso para propiciar adequação de tais elementos às necessidades do contexto em que desempenham seu trabalho, em uma via de aprendizagens e redirecionamentos de estratégias, que possam impactar nos processos de ensino e de aprendizagem (NASCIMENTO et al., 2018). 
A ausência de diálogo, no contexto de iniciação profissional do professor convidado, evidencia-se como um entrave à sua aprendizagem e ao desenvolvimento no âmbito da profissão exercida, devido à questão individualizadora que imperava no ambiente de trabalho. Esse fator pode repercutir na acomodação e no delineamento de práticas repetitivas, em decorrência da sobrevivência na profissão (WIEBUSCH; CUNHA, 2014).

Nesse aspecto, tornam-se necessários o acolhimento e a orientação aos professores em início de carreira, de forma que estes possam sentir-se integrantes do ambiente escolar em que atuam e construir espaços dialógicos de aprendizagem da profissão, pautados pela mobilização de elementos comuns que almejem a melhoria coletiva da prática docente e da escola. A finalidade é contribuir e estimular o processo de desenvolvimento no âmbito da profissão.

Após o posicionamento do docente convidado, o Estudante 2 afirmou:

É importante o trabalho colaborativo no âmbito da docência em Matemática, em que os professores possam interagir e dialogar, fomentar aprendizagens e ampliar o conhecimento, objetivando aulas mais qualificadas e que propiciem momentos de aprendizagem aos alunos, não apenas uma aula monótona e de repetição de conceitos, que não estimule os alunos a pensar, apenas contribui na visão negativa da Matemática escolar, se constituindo como fator de exclusão e rejeição ao conhecimento disciplinar. (Estudante 2. Dados da pesquisa).

Nessa perspectiva, Oliveira-Formosinho (2009) reforça tal afirmação ao expor que a instauração de ambientes coletivos de aprendizagem contribui na troca mútua de conhecimentos que tendem a melhorar a prática do professor, o que repercute, também, em aspectos pessoais. Nesses termos, devem ser oportunizados o diálogo entre os pares, a busca consensual por objetivos comuns e compartilhados, de forma a evocar o espírito de grupo entre os professores que compõem uma escola.

\section{Prática do professor}

A Estudante 3 questionou o docente convidado sobre sua prática docente. Ela indagou o seguinte: "Quais as potenciais estratégias que podem contribuir na aprendizagem da docência em Matemática?”. O professor explicitou:

\footnotetext{
Não existe uma fórmula pronta e acabada, apenas para execução e reprodução, uma vez que esse processo permeia a análise reflexiva docente, mediada pelos impactos provenientes da ação no âmbito da sala de aula, em que o professor deve ouvir a opinião dos alunos e dos colegas de profissão, desconstruir e reconstruir sua prática, fundamentada em uma teoria que a sustente e direcionada às necessidades dos educandos e do contexto em que desenvolve sua atividade profissional. (Professor de Matemática. Dados da pesquisa).
}

A perspectiva desse docente coaduna com o enunciado por Lima (2012), ao afirmar que a ação do professor se configura em uma atividade solitária e individualizada, no contexto da sala de aula, em que a observação por parte dos pares e a opinião crítica dos alunos devem ser consideradas, constituindo-se em momentos de busca por aperfeiçoamento das estratégias didático-pedagógicas que possam reverberar em uma melhor atuação profissional. Para complementar, Freire (2009) expõe que o diálogo potencializa a participação e o engajamento dos indivíduos, por intermédio da escuta atenta e reflexiva, objetivando a mobilização, a interpretação e as inferências, com foco em melhorias individuais e coletivas.

As situações reais de ensino no âmbito da sala de aula evidenciam-se como oportunidades de aprendizagem para discentes e docentes, em uma via de ressignificação das ações práticas do

Práxis Educativa, Ponta Grossa, v. 16, e2116556, p. 1-14, 2021

Disponível em: <https://www.revistas2.uepg.br/index.php/praxiseducativa> 
professor. Delineiam-se, assim, preceitos direcionados aos anseios e às necessidades reais dos educandos, para avaliar os impactos provenientes da sua atuação, em uma "[...] postura reflexiva, pois esta proporciona ao educador um olhar mais consciente e crítico do seu papel como transformador social, político e cultural” (BEHRENS; CARPIM, 2013, p. 113).

Enfatiza-se que a atuação do professor no âmbito escolar não deve remeter-se a um praticismo exacerbado, sem direcionamento, apenas enfocando a prática por si mesma, fator que pode desestimular o professor, esgotar suas energias física e mental. Em contrapartida, evoca-se um planejamento direcionado às necessidades dos alunos e da escola, conforme análises reflexivas e estudos pessoais individualizados e coletivos, em uma via que vincule teoria e prática, ambas dialogando e uma ressignificando a outra (PIMENTA; LIMA, 2012).

\title{
Condições efetivas de trabalho
}

O Estudante 4 fez a seguinte indagação: "Quais as condições de trabalho disponibilizadas para sua ação profissional?”. Para responder a esse questionamento o docente afirmou:

\begin{abstract}
$\mathrm{Na}$ minha realidade, as condições de trabalho não se configuram como um elemento conducente a um exercício profissional qualitativo, em que já me deparei com fatores adversos, como a quantidade de alunos por turma - cheguei a lecionar em turmas com 47 alunos) -, bem como as salas de aula pouco arejadas, em decorrência de habitarmos uma região semiárida nordestina, caracterizada por temperaturas elevadas; exigências acerca de índices qualitativos de aprendizagem por parte de organismos educacionais e da própria sociedade, dissonantes da realidade de trabalho dos professores e das escolas. (Professor de Matemática. Dados da pesquisa).
\end{abstract}

Em seu estudo sobre as condições de trabalho inerentes aos professores de Matemática em início de carreira, Nascimento et al. (2019) afirmam que tais preceitos não se configuram como fatores contribuintes na vida e no trabalho docente, visto que as expectativas criadas acerca da ação educacional como elemento de promoção e de transformação social se contrapõem ao fato de somente a escola e os agentes que a compõem exercerem a função executora de premissas e preceitos estipulados, em uma via de mão única. Nesse sentido, a sociedade e os organismos político-educacionais apenas estipulam o que deve ser feito, mas se omitem de suas responsabilidades na busca pelo diálogo e pelo desenvolvimento de ações conjuntas que possam repercutir na qualidade da educação.

A efetivação da qualidade educacional permeia o estabelecimento dialógico entre organismos político-educacionais, sociedade em geral, professores e escolas. Nessa acepção, delineiam-se ações em consonância com a realidade das instituições escolares, e não apenas à idealização de fatores utópicos que desconsideram a opinião e as condições de vida e de trabalho dos profissionais da educação. Disponibilizam-se, assim, recursos humanos e materiais, bem como o engajamento e a mobilização coletiva de todos os agentes, e não apenas das escolas e dos professores com incumbência executora de preceitos delineados por outros que não vivenciam a realidade cotidiana da educação.

\section{Formação contínua}

O Estudante 5 discorreu sobre a questão formativa ao longo da vida docente e perguntou o seguinte: "Qual a relevância da formação contínua na atuação do professor de Matemática?". Acerca dessa indagação, o professor convidado expôs o seguinte: 
A formação contínua deve se constituir como algo que acompanhe a carreira docente, mediada por necessidades relacionadas ao desenvolvimento/aperfeiçoamento de aspectos relacionados à ressignificação de conhecimentos que perpassam à docência, sejam estes de cunho específico e/ou didático-pedagógicos, reverberando em fatores pessoais e inerentes ao trabalho na profissão. Nesse aspecto, os professores em serviço necessitam de tempo, espaços adequados, condições propícias de ensino e auxílio por parte da gestão e dos colegas para potenciais mudanças em sua prática, que é um processo lento e gradual, em que se requer apoio na implementação de novos aportes e de análise dos seus resultados. (Professor de Matemática. Dados da pesquisa).

Nesse viés, Lima (2012) expõe que o profissional da educação deve perceber a importância da aprendizagem constante da docência, em que a formação esteja atrelada às suas condições de vida e trabalho. Dessa maneira, ele aprende continuamente, torna-se um professor mais qualificado, e tal fator também repercute em sua vida pessoal, bem como em formas de ser e estar na docência.

Ao compartilharem dessa mesma percepção, Nascimento, Araújo e Lima (2017) acrescentam que os objetivos e os conteúdos trabalhados no percurso da formação contínua devem enfocar as necessidades da prática docente e partir dos dilemas e das querelas enfrentados no cotidiano. Devem considerar, também, os saberes e as experiências dos profissionais, em que os professores em exercício possam ser protagonistas e participantes do processo e não meros sujeitos receptores de informações, em um princípio formativo idealizado que não repercute na ação docente por estar em dissonância com seus anseios e suas necessidades.

Observa-se, ainda, que o processo formativo contínuo deve ser ofertado como política de Estado e em consonância com o que os professores em serviço almejam e necessitam, desde o período de iniciação na profissão. A formação contínua deve ser considerada como componente essencial da profissionalização, inspirada nos diferentes saberes e na experiência docente e integrada ao cotidiano da escola e do projeto pedagógico da instituição de Educação Básica (PIMENTA; LIMA, 2012).

Explicita-se, portanto, a necessidade da articulação entre a formação inicial e contínua (na qual a formação continuada está inserida), em que as necessidades dos professores e dos contextos sejam consideradas no desenvolvimento do processo, com vistas a reverberar na vida e no trabalho docente, assim como na instituição em que desenvolvem seu trabalho cotidiano.

\section{Atuação do professor de Matemática no âmbito da sala de aula}

A Estudante 6 evidenciou a indagação seguinte: "Quais as possibilidades de ação no âmbito da sala de aula, de forma a despertar interesse pela aprendizagem Matemática?”. O docente da Educação Básica explicitou o seguinte:

É importante o estabelecimento do diálogo no ambiente da sala de aula, configurandose como elemento mediador e de tracejamento de metas e objetivos compartilhados, em que os estudantes possam se sentir estimulados a opinarem acerca de fatores que os afetam, remetendo ao delineamento do processo de ensino, bem como participem efetivamente da construção do seu conhecimento, com responsabilidades e compromisso para com os estudos. Além disso, é relevante o trabalho com conhecimentos prévios dos alunos, mediante a utilização de tal aspecto como mote analítico para o planejamento e execução de estratégias, partindo do que os alunos sabem, no intuito de avançar no estudo dos conteúdos, contextualizando o processo sem perder de vista o rigor científico da disciplina, como ciência presente e atuante no cotidiano. (Professor de Matemática. Dados da pesquisa).

Nesses termos, o diálogo, conforme Freire (2009), expõe-se como premissa comunicativa de estabelecimento de objetivos comuns e de respeito mútuo nas discussões sobre um determinado

Práxis Educativa, Ponta Grossa, v. 16, e2116556, p. 1-14, 2021 
fator, em que o foco resida no coletivo, naquilo que propicie melhorias conjuntas e compartilhadas, permeando a consciência crítica e emancipatória. Para complementar, Braga (2015) afirma que, no âmbito da sala de aula, permeiam questões disciplinares, as quais permitem que o diálogo potencialize a instauração de um ambiente conducente e facilitador da aprendizagem e os estudantes percebam a necessidade de momentos de discussões e de interações, bem como de silêncio e de atenção ao docente, em um respeito mútuo e cooperação entre professores e alunos.

O momento dialógico formativo foi encerrado por meio da intervenção da professora titular de sala, que inquiriu os licenciandos acerca de possíveis questionamentos e dúvidas. Os alunos expuseram, assim, que as perguntas e as respostas, provenientes do diálogo, contemplaram os anseios, as dúvidas e as indagações coletivas e individuais dos professores de Matemática em formação.

Realizou-se, então, uma breve avaliação da experiência formativa dialógica. Os licenciandos e o professor convidado expuseram a relevância do momento, dada a oportunidade singular de compartilhamento de conhecimentos e de experiências inerentes ao exercício do professor de Matemática. Cada sujeito, com características e singularidades próprias, contribuiu no diálogo e na formação do colega e evidenciou fatores que poderão auxiliar os formandos em sua inserção profissional e na ressignificação do trabalho exercido pelo professor que já atua na docência.

Enfatizam-se as dificuldades de realização da atividade desta pesquisa, as quais perpassaram pela carga horária de trabalho do professor da Educação Básica. A ação teve de ser remarcada algumas vezes pelo fato de o convidado exercer uma jornada de trabalho diária de oito horas e pelo tempo de duração da atividade, que foi realizada em três horas. Além disso, houve a necessidade de aprofundamento no debate acerca de aspectos e de fatores que interferem e impactam na ação docente, em uma via problematizadora, produtora de inferências que evidenciem e potencializem melhorias coletivas, em consonância com o diálogo freireano.

Entretanto, considera-se exitosa a proposta pela oportunidade inicial de estabelecimento dialógico entre licenciandos e professor convidado, cuja perspectiva foi contribuir com uma formação robusta que beneficie a todos os envolvidos, com melhorias coletivas que almejem um processo de ensino e de aprendizagem mais qualificado, em que o diálogo se configure como elemento mediador.

\section{Considerações finais}

A formação inicial deve englobar o princípio equitativo entre conhecimentos específicos e didático-pedagógicos, de modo que ao futuro professor sejam oportunizados momentos de atrelamento entre tais saberes e culmine no processo de identificação com a profissão ou de afastamento dela. Uma vez que a docência é aprendida, ela requer formação e constante atualização. Advoga-se, também, o contato com profissionais mais experientes para que os licenciandos possam inquiri-los, em resposta a questionamentos individuais e coletivos que perpassam o ofício educativo.

A edificação deste escrito fundamentou-se nos pressupostos citados anteriormente. A realização da experiência evidenciou a relevância dialógica, pautada nos princípios freireanos, em um espaço de produção/sistematização de conhecimentos que objetivaram a transformação da realidade, com professores que estabelecessem uma relação afetuosa com seus educandos, não um amor ingênuo e alienante, mas crítico e emancipatório, promotor de engajamento na luta de classes, com foco na melhoria coletiva. 
A realização da atividade evidenciou a importância do diálogo na construção de conhecimentos e a efetivação da democracia nos espaços acadêmicos e escolares, objetivando um processo de ensino matemático mais qualificado e que reverbere na aprendizagem discente, de forma a fortalecer o Estágio Supervisionado como oportunidade de contato com práticas e saberes diversificados, além do conhecimento da complexidade que permeia a escola. Em outro momento, almeja-se que todos os licenciandos possam ir a uma instituição escolar participar do planejamento coletivo e de ações promotoras de efetivação dialógica e de compartilhamento de saberes e experiências no lócus de atuação do professor: a escola.

À guisa de conclusão, enfatiza-se que esta pesquisa se constituiu em uma tentativa incipiente de inserção da dialogicidade freireana no cotidiano formativo docente. No entanto, para alcançarse a profundidade da proposta desenvolvida por Paulo Freire nos círculos de cultura, outras etapas deverão ser desenvolvidas, sobretudo com maior aprofundamento das problematizações/discussões aqui apresentadas. Todavia, ressalta-se que esta proposta se mostrou como um passo inicial potente, para a inserção do diálogo enquanto elemento formativo docente, principalmente em virtude das devolutivas positivas por parte dos licenciandos e do professor da Educação Básica, participantes desse momento.

\section{Referências}

ANDRÉ, M. O que é um estudo de caso qualitativo em educação? Revista da FAEEBA Educação e Contemporaneidade, Salvador, v. 22, n. 40, p. 95-103, 2013. DOI: https://doi.org/10.21879/faeeba2358-0194.2013.v22.n40.p95-103

BARDIN, L. Análise de conteúdo. São Paulo: Edições 70, 2011.

BEHRENS, M. A.; CARPIM, L. A formação dos professores de educação profissional e o desafio do paradigma da complexidade. In: PRYJMA, M. (org.). Desafios e trajetórias para o desenvolvimento profissional docente. Curitiba: UTFPR, 2013. p. 103-135.

BRAGA, M. M. S. de C. Prática pedagógica docente-discente: traços da pedagogia de Paulo Freire na sala de aula. Recife: Editora UFPE, 2015.

BRASIL. Lei $\mathbf{N}^{\mathbf{0}}$ 12.289, de 20 de julho de 2010. Criação da Universidade da Integração Internacional da Lusofonia Afro-Brasileira. Brasília: Presidência da República, Casa Civil, Subchefia para Assuntos Jurídicos [2010]. Disponível em: http://www.planalto.gov.br/ccivil_03/_ato20072010/2010/lei/112289.htm. Acesso em: 24 abr. 2020.

FRANCO, M. A. do R. S. Da necessidade/atualidade da Pedagogia Crítica: crítica, contributos de Paulo Freire. Revista Reflexão e Ação, Santa Cruz do Sul, v. 25, n. 2, p. 152-170, 2017. DOI: https://doi.org/10.17058/rea.v25i2.8891

FREIRE, P. A educação na cidade. 7. ed. São Paulo: Cortez, 2006.

FREIRE, P. Pedagogia do oprimido. 48. ed. São Paulo: Paz e Terra, 2009.

FREIRE, P. Extensão ou comunicação? 13. ed. São Paulo: Paz e Terra, 2011.

FREIRE, P. Pedagogia da esperança: um reencontro com a Pedagogia do oprimido. 26. ed. São Paulo: Paz e Terra, 2012.

FREIRE, P. Educação como prática da liberdade. 44. ed. São Paulo: Paz e Terra, 2013. 
IBGE. Instituto Brasileiro de Geografia e Estatística. Regiões de influência das cidades: 2018. Coordenação de Geografia. Rio de Janeiro: IBGE, 2020.

LIMA, M. S. L. Estágio e aprendizagem da profissão docente. Brasília: Liber Livro, 2012.

LOPES, A. R. L. V. Aprendizagem da docência em matemática: o clube da matemática como espaço de formação inicial de professores. Passo Fundo: Editora Universidade de Passo Fundo, 2009.

NASCIMENTO, F. J. do; ARAÚJO, R. R.; LIMA, M. S. L. Pacto nacional pelo fortalecimento do ensino médio: ressignificando a formação continuada de professores. Revista COCAR, Belém, v. 11, n. 21, p. 117-141, jan./jun. 2017. DOI: https://doi.org/10.31792/rc.v11i21

NASCIMENTO, F. J. do et al. Professores iniciantes de matemática: um estudo sobre seu desenvolvimento profissional. Revista VÉRTICES, Campos dos Goytacazes, v. 20, n. 1, p. 111 119, abr. 2018. DOI: https://doi.org/10.19180/1809-2667.v20n12018p111-119

NASCIMENTO, F. J. do et al. Condições de trabalho de professores iniciantes de Matemática: possibilidades e desafios no processo de desenvolvimento profissional. Horizontes, Itatiba, v. 37, n. 1, p. 1-28, mar. 2019. DOI: https://doi.org/10.24933/horizontes.v37i0.626

NERY, V. C. G.; BARBOSA, A. M. S. A humanização Freiriana: processos de formação docente nos documentos que orientam os currículos dos cursos de Pedagogia. Práxis Educativa, Ponta Grossa, v. 16, e2116218, p. 1-21, 2021. DOI: https://doi.org/10.5212/PraxEduc.v.16.16218.026

NÓVOA, A. Professores - imagens do futuro presente. Lisboa: Educa, 2009.

OLIVEIRA, I. A. A dialogicidade na educação de Paulo Freire e na prática do ensino de filosofia com crianças. Movimento-Revista de Educação, Niterói, v. 4, n. 7, p. 228-253, 2017. DOI: https://doi.org/10.22409/mov.v0i7.414

OLIVEIRA-FORMOSINHO, J. Desenvolvimento profissional de professores. In: FORMOSINHO, J. (org.). Formação de professores - aprendizagem profissional e acção docente. Porto: Porto editora, 2009. p. 221-284.

PIMENTA, S. G.; LIMA, M. S. L. Estágio e docência. 7. ed. São Paulo: Cortez, 2012.

SANTOS, J. M. C. T.; RODRIGUES, P. J. M. O diálogo como possibilidade de mediação da violência na escola. Práxis Educativa, Ponta Grossa, v. 8, n. 1, p. 273-294, jan./jun. 2013. DOI: https://doi.org/10.5212/praxeduc.v.8i1.0011

SEVERINO, A. J. Dimensão ética da investigação científica. Práxis Educativa, Ponta Grossa, v. 9, n. 1, p. 199-208, 2014. DOI: https://doi.org/10.5212/praxeduc.v.9i1.0009

WIEBUSCH, E. M.; CUNHA, M. I. A profissionalidade dos professores iniciantes na educação profissional e tecnológica: um desafio para a gestão? Revista de Administração Educacional, Recife, v. 1, n. 1, p. 30-42, 2014.

Recebido em 04/08/2020

Versão corrigida recebida em 24/04/2021

Aceito em 25/04/2021

Publicado online em 03/05/2021

Práxis Educativa, Ponta Grossa, v. 16, e2116556, p. 1-14, 2021

Disponível em: <https://www.revistas2.uepg.br/index.php/praxiseducativa> 